\title{
Fluorescent Analysis of Translesion DNA Synthesis by Using A Novel, Non-natural Nucleotide Analogue
}

Irene Lee

Case Western Reserve University

Anthony J. Berdis

Cleveland State University, A.BERDIS@csuohio.edu

Follow this and additional works at: https://engagedscholarship.csuohio.edu/scichem_facpub

Part of the Biochemistry Commons, and the Chemistry Commons

How does access to this work benefit you? Let us know!

\section{Publisher's Statement}

This is the accepted version of the following article: Lee, I.; Berdis, A. Fluorescent Analysis of Translesion DNA Synthesis by Using a Novel, Non-natural Nucleotide Analogue. ChemBioChem 2006, 7, 1990-1997., which has been published in final form at http://onlinelibrary.wiley.com/doi/ 10.1002/cbic. $200600128 /$ pdf

\section{Recommended Citation}

Lee, Irene and Berdis, Anthony J., "Fluorescent Analysis of Translesion DNA Synthesis by Using A Novel, Non-natural Nucleotide Analogue" (2006). Chemistry Faculty Publications. 195.

https://engagedscholarship.csuohio.edu/scichem_facpub/195

This Article is brought to you for free and open access by the Chemistry Department at EngagedScholarship@CSU. It has been accepted for inclusion in Chemistry Faculty Publications by an authorized administrator of EngagedScholarship@CSU. For more information, please contact library.es@csuohio.edu. 


\title{
Fluorescent Analysis of Translesion DNA Synthesis by Using a Novel, Non-natural Nucleotide Analogue
}

\author{
Irene Lee and Anthony Berdis
}

The replication of damaged DNA is a promutagenic process that can lead to disease development. This report evaluates the dynamics of nucleotide incorporation opposite an abasic site, a commonly formed DNA lesion, by using two fluorescent nucleotide analogues, 2-aminopurine deoxyribose triphosphate (2-APTP) and 5-phenylindole deoxyribose triphosphate (5-Ph/TP). In both cases, the kinetics of incorporation were compared by using a ${ }^{32} \mathrm{P}$-radiolabel extension assay versus $a$ fluorescence-quenching assay. Although 2-APTP is efficiently incorporated opposite a templating nucleobase (thymine), the kinetics for incorporation opposite an abasic site are significantly slower. The lower catalytic efficiency hinders its use as a probe to study translesion DNA syn-

\section{Introduction}

Abasic sites are a commonly formed class of DNA lesion that are devoid of hydrogen-bonding potential. ${ }^{[1]}$ Although this is a nontemplating DNA lesion, several DNA polymerases including the bacteriophage T4 DNA polymerase, gp43, preferentially incorporate dATP opposite an abasic site. ${ }^{[2,3]}$ The mechanism accounting for this preferential utilization of a specific dNTP has been extensively studied structurally and kinetically. ${ }^{[3 a, 4]}$ Recent structural analyses obtained with the polymerase poised at an abasic site indicate the presence of at least two distinct conformations of the incorporated nucleotide when placed opposite the DNA lesion. ${ }^{[4]}$ In addition, significant differences in the geometry of the DNA bound at the polymerase's active site were noted during translesion DNA synthesis compared to normal DNA replication. These structural differences arguably reflect a change in the dynamics of the conformational-change step that precedes phosphoryl transfer. Indeed, based upon the results of steady-state and transient kinetic studies monitoring the incorporation of dATP opposite this lesion, this kinetic step was initially proposed to be rate-limiting for translesion DNA synthesis..$^{[2,5]}$ Unfortunately, a clear understanding of the dynamics of the conformational change during correct or promutagenic DNA synthesis still remains elusive.

In this report, we have probed the kinetics of the conformational-change step by characterizing the incorporation of two fluorescent nucleotide analogues opposite an abasic site. The first analogue tested was 2-aminopurine deoxyribose triphosphate (2-APTP), a highly fluorescent constitutional analogue of dATP (Scheme 1) that has been used extensively to monitor the dynamics of normal replication, that is, incorporation op- thesis. In contrast, the rate constant for the incorporation of 5 PhITP opposite the DNA lesion is 100-fold faster than that for 2APTP. Nearly identical kinetic parameters are obtained from fluorescence quenching or the ${ }^{32} P$-radiolabel assay. Surprisingly, distinct differences in the kinetics of 5-PhITP incorporation opposite the DNA lesion are detected when using either bacteriophage T4 DNA polymerase or the Escherichia coli Klenow fragment. These differences suggest that the dynamics of nucleotide incorporation opposite an abasic site are polymerase-dependent. Collectively, these data indicate that 5-PhITP can be used to perform realtime analyses of translesion DNA synthesis as well as to functionally probe differences in polymerase function. posite templating DNA. For example, 2-aminopurine can form a normal Watson-Crick base pair with thymine or a wobble base pair with $C^{[6]}$ More importantly, the fluorescence of 2-AP

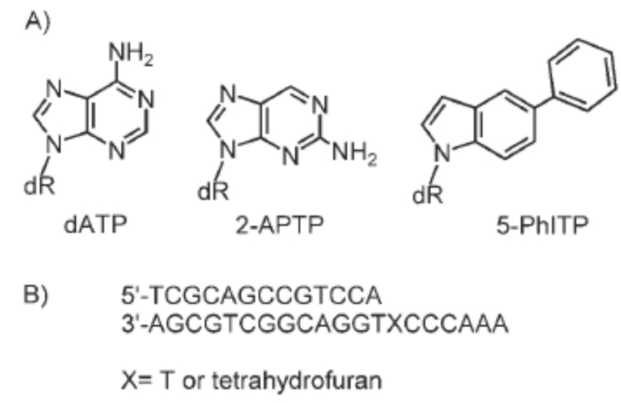

Scheme 1. A) Structures of 2 aminopurine triphosphate (2 APTP) and 5 phenyl indolyl 2 ' deoxyriboside triphosphate (5 PhITP). For convenience, $d R$ is used to represent the deoxyribose triphosphate portion of the nucleo tides. B) Defined DNA substrates used for kinetic analysis. " $X$ " in the tem plate strand denotes thymine $(13 / 20 \mathrm{~T}$ mer) or a tetrahydrofuran moiety that functionally mimics an abasic site (13/20SP mer). 
is strongly quenched through base-stacking interactions with nucleic acid; this makes it a sensitive probe for local and global changes in DNA conformation that are influenced by DNA polymerization and exonuclease activities. ${ }^{[7]}$ Most biochemical studies monitoring the fluorescence quenching of 2aminopurine place the nucleotide analogue probe into nucleic acid. In these instances, the fluorescence of 2-aminopurine is quenched approximately twofold when placed opposite a templating partner such as $\mathrm{T}$ or $\mathrm{C}$. This change in fluorescence makes 2-aminopurine a powerful probe of nucleic acid conformations going from single- to double-stranded DNA and vice versa. Indeed, Frey et al. were amongst the first to quantify the kinetics of dTTP incorporation opposite 2-AP using gp43exoas the model system. ${ }^{[7]}$ Their studies demonstrated the existence of a conformational-change step preceding phosphoryl transfer with two different DNA polymerases (the Klenow fragment of E. coli and the bacteriophage T4 DNA polymerase). Furthermore, the kinetics of dTTP incorporation opposite 2aminopurine were essentially identical to that measured for dTTP incorporation opposite $A$, the natural templating partner.

The other analogue tested in this study is 5-phenylindole deoxyribose-5'-triphosphate (5-PhITP), a non-natural nucleotide that is efficiently incorporated opposite an abasic site by gp43. ${ }^{[5]}$ The overall catalytic efficiency for the incorporation of 5-PhITP opposite an abasic site is 1000-fold greater than the incorporation of dATP..$^{[5]}$ The higher catalytic efficiency for translesion DNA synthesis is proposed to reflect the large $\pi$ electron surface area of the non-natural nucleotide. ${ }^{[5]}$ Furthermore, the highly conjugated system present on this analogue can be used as a fluorescent probe to monitor the dynamics of nucleotide incorporation opposite this non-templating DNA lesion.

This report compares the ability of 2-APTP and 5-PhITP to act as fluorogenic probes to measure the dynamics of translesion DNA synthesis. Unfortunately, 2-APTP is poorly incorporated opposite an abasic site and this limits its utility as a selective probe for translesion DNA synthesis. However, we find that 5-PhITP is an excellent probe since it is rapidly inserted opposite the lesion even at low concentrations $(<4 \mu \mathrm{M})$. Collectively, this work provides the first demonstration of a realtime probe to monitor the dynamics of translesion DNA synthesis.

\section{Results and Discussion}

\section{Analyses of 2-APTP incorporation opposite an abasic site versus templating DNA}

The ability to use 2-aminopurine as a surrogate for adenine prompted us to evaluate its utility as a probe for translesion DNA synthesis. Specifically, we extended this approach to directly monitoring the incorporation of 2-APTP opposite an abasic site, a noncoding DNA lesion. However, these experiments are more technically challenging than those with 2-APcontaining DNA since the concentration of the nucleotide 2APTP must be maintained at a low value (less than $5 \mu \mathrm{M}$ ) due to its high intrinsic fluorescence while free in solution. This complication necessitates the use of single-turnover reaction conditions to maximize the signal-to-noise ratio for incorporation. To validate this approach, we first compared the incorporation of 2-APTP opposite $\mathrm{T}$ by the fluorescence-quenching assay versus a ${ }^{32} \mathrm{P}$-radiolabel assay that monitors primer extension. As noted above, reactions were performed under singleturnover conditions, under which the concentrations of DNA and gp43exo ${ }^{-}$were maintained at $500 \mathrm{~nm}$ and $1 \mu \mathrm{M}$, respectively, while the concentration of 2-APTP was fixed at $2 \mu \mathrm{M}$. For fluorescence-quenching studies, the kinetics of 2-APTP incorporation were monitored by excitation at $310 \mathrm{~nm}$ and measuring fluorescence emission by using a cut-off filter that measures emission wavelengths greater than $340 \mathrm{~nm}$. Figure $1 \mathrm{~A}$
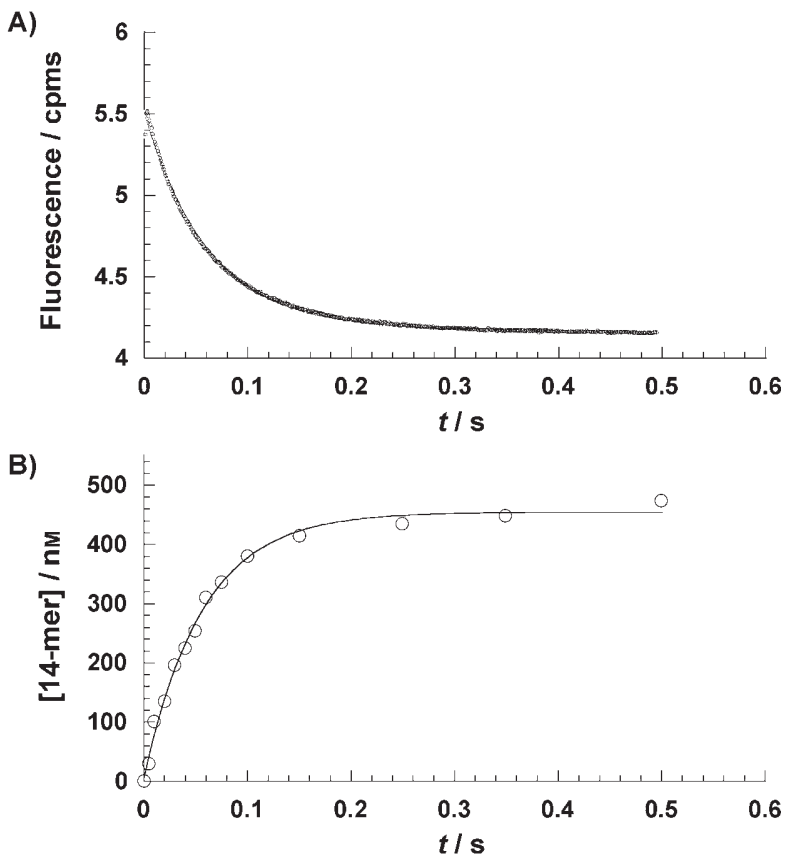

Figure 1. Comparison of the kinetics of nucleotide insertion by using radiola beled versus fluorescence quenching under single turnover conditions. Time course monitoring of the incorporation of 2 APTP opposite T by gp43 exo by using $\mathrm{A}$ ) the fluorescence quenching assay or $\mathrm{B}$ ) the radiolabel extension assay.

provides a representative stopped-flow time course for the incorporation of 2-APTP opposite T. The decrease in fluorescence as a function of time reflects base-stacking interactions of the nucleotide associated with its incorporation into duplex DNA. ${ }^{[8]}$ The time course is best defined as a single-exponential curve, and a fit of the data to Equation (2) (below) yields an observed rate constant, $k_{\mathrm{obs}}$ of $15.8 \pm 0.1 \mathrm{~s}^{-1}$. Figure $1 \mathrm{~B}$ shows the time course monitoring of 2-APTP incorporation by using the radiolabeled assay performed under identical reaction conditions. This time course is also best defined as a single-exponential curve from which a $k_{\text {obs }}$ value of $17.6 \pm 1.0 \mathrm{~s}^{-1}$ is obtained. The accuracy of these rate constants was verified by applying these values to the Michaelis-Menten equation $\left(k_{\mathrm{obs}}=k_{\mathrm{pol}} \times 2\right.$-APTP/ $\left(K_{\mathrm{d}}+2\right.$-APTP)). With the reported $k_{\text {pol }}$ value of $100 \mathrm{~s}^{-1}$ and a $K_{\mathrm{d}}$ of $10 \mu \mathrm{m}$ for 2-APTP opposite T, the calculated $k_{\text {obs }}$ value for 
$2 \mu \mathrm{M}$ 2-APTP is $16.7 \mathrm{~s}^{-1}$. [7a] This value is in excellent agreement with the measured kinetic values from either the radiolabel $\left(17.6 \mathrm{~s}^{-1}\right)$ or the fluorescence-quenching assay $\left(15.8 \mathrm{~s}^{-1}\right)$. In addition, these rate constants are consistent with the reported values measured for the incorporation of dTTP opposite 2$A P{ }^{[7 a]}$ The identity of these rate constants (within experimental error) is consistent with previous studies indicating that basestacking of 2-aminopurine occurs concomitantly with the conformational change preceding phosphoryl transfer. ${ }^{[7 a]}$

An identical strategy was used to monitor the incorporation of 2-APTP opposite an abasic site. Figure $2 \mathrm{~A}$ shows the time course in fluorescence quenching of 2-aminopurine during in-

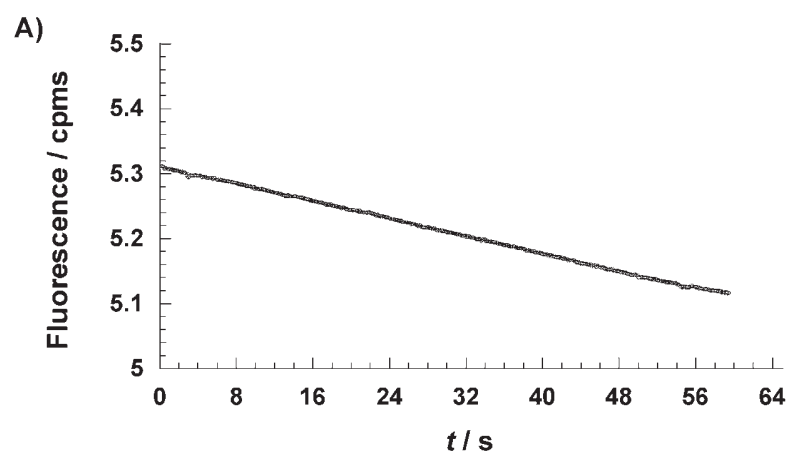

B)

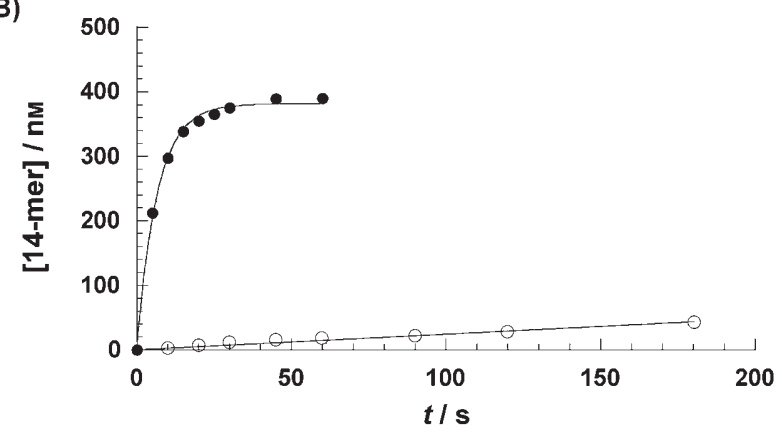

Figure 2. Time course monitoring of the incorporation of A) $2 \mu \mathrm{M} 2$ APTP opposite an abasic site by gp43 exo by using the fluorescence quenching assay. B) $2 \mu \mathrm{M}(\circ)$ or $500 \mu \mathrm{M}(\bullet) 2$ APTP opposite an abasic site by gp43 exo by using the radiolabel extension assay. Assays were performed as described in the text.

corporation opposite an abasic site. Despite the use of singleturnover reaction conditions, the time course is linear and unfortunately cannot provide a defined rate constant for incorporation. The poor fluorescence quenching of 2-APTP opposite the abasic site could represent poor kinetic parameters for insertion opposite damaged DNA (high $K_{\mathrm{d}}$ and/or low $k_{\text {pol }}$ values) and/or inefficient quenching due to the nontemplating nature of the abasic site. These possibilities were evaluated by monitoring the rate of 2-APTP incorporation by using the radiolabeled assay under identical reaction conditions. The time course provided in Figure 2B also shows a slow, linear rate of incorporation that mimics that obtained in the fluorescencequenching assay. It should be noted, however, that the rate constant for 2-APTP incorporation increases as the concentration is increased from 2 to $500 \mu \mathrm{M}$ (Figure $2 \mathrm{~B}$ ). The rate con- stant measured for the incorporation of $500 \mu \mathrm{M}$ 2-APTP is $0.15 \pm 0.01 \mathrm{~s}^{-1}$, a value identical to the $k_{\mathrm{pol}}$ of $0.15 \mathrm{~s}^{-1}$ measured by using the preferred natural nucleotide, dATP. ${ }^{[2]}$ These data collectively indicate that 2-APTP is similar to dATP as both are inefficiently incorporated opposite an abasic site.

The slow kinetics in fluorescence quenching could also reflect altered quenching capabilities of the nucleotide when placed opposite an abasic site. To evaluate this possibility, we compared the fluorescent changes associated with 2-APTP incorporation opposite $\mathrm{T}$ versus opposite an abasic site. The change in fluorescence intensity with abasic site-containing DNA is nearly identical to that with unmodified DNA (see Figure S1 in the Supporting Information) and verifies that the fluorescence of 2-APTP can be quenched opposite abasic sites. These data are consistent with published results from Stiver's laboratory demonstrating that fluorescent quenching of 2-aminopurine occurs opposite an abasic site with nearly identical efficiency as when placed opposite templating DNA. ${ }^{[9]}$ It is clear that 2-APTP can be used to monitor the dynamics of nucleotide incorporation opposite undamaged DNA. However, its utility toward accurately evaluating translesion DNA synthesis is limited due to its poor kinetic behavior for incorporation opposite an abasic site.

\section{Kinetic analyses of 5-PhITP incorporation opposite an abasic site}

The dynamics of 5-PhITP incorporation opposite an abasic site were next measured to evaluate its potential use as a spectroscopic probe of translesion DNA synthesis. The advantage of 5PhITP is that gp43 exo ${ }^{-}$efficiently incorporates this non-natural nucleotide opposite an abasic site with a low $K_{d}$ of $\sim 10 \mu \mathrm{M}$ and a fast $k_{\text {pol }}$ of $\sim 50 \mathrm{~s}^{-1} \cdot{ }^{[5]}$ Furthermore, the molecule contains an extended aromatic ring system that is predicted to be highly fluorescent while free in solution but that should be quenched once incorporated opposite the abasic site. Finally, the T4 DNA polymerase is unable to extend beyond this analogue once incorporated opposite an abasic site. ${ }^{[5]}$ Thus, the chain termination capabilities of 5-PhITP predicts a stoichiometry of one incorporation event per abasic site.

Time courses for 5-PhITP incorporation opposite an abasic site were measured as described above by using the fluorescence-quenching assay (Figure $3 \mathrm{~A}$ ) or the radiolabeled assay (Figure $3 \mathrm{~B}$ ). Both time courses are best defined as single-exponential processes and were fitted to the corresponding equation to define rate constants for incorporation. The $k_{\text {obs }}$ value from the fluorescent quenching assay is $7.7 \pm 0.1 \mathrm{~s}^{-1}$, while that from the radiolabeled assay is $6.4 \pm 0.4 \mathrm{~s}^{-1}$. Each value represents an average of four independent determinations performed on separate occasions. The rate constant of $\sim 7 \mathrm{~s}^{-1}$ measured with $2 \mu \mathrm{M} 5$-PhITP is at least 100 -fold faster than those measured with $2 \mu \mathrm{m}$ 2-APTP. The faster rate constant indicates that 5-PhITP can be used as a convenient probe to monitor the kinetics of translesion DNA synthesis.

The kinetic dissociation constant $\left(K_{\mathrm{d}}\right)$ and the maximal rate constant for the fluorescence quenching $\left(k_{\max q u e n c h}\right)$ of 5-PhITP opposite an abasic site were determined by varying the con- 

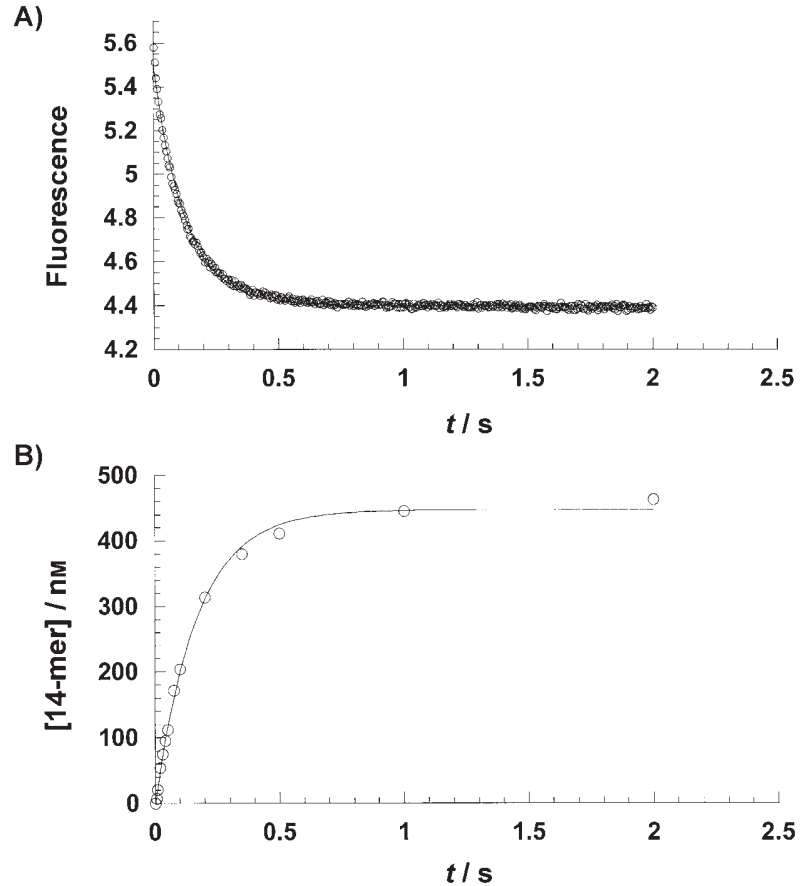

Figure 3. Time course monitoring of the incorporation of 5 PhITP opposite an abasic site by gp43 exo by using A) the fluorescence quenching assay or B) the radiolabel extension assay. Assays were performed as described in the text.

centration of 5-PhITP from 4 to $64 \mu \mathrm{M}$ under single-turnover reaction conditions. Representative data for the concentration dependency of 5-PhITP on fluorescence quenching are provided in Figure 4A. As expected, the amplitude in fluorescence quenching decreases as the concentration of 5-PhITP increases. The reduction in signal-to-noise ratio prohibits detecting a change in fluorescence caused by incorporation when using nucleotide concentrations greater than $32 \mu \mathrm{m}$. Regardless, the time courses generated with 5 -PhITP concentrations $\leq 32 \mu \mathrm{m}$ were fitted to the equation for a single-exponential decay to define $k_{\text {quench, }}$ the rate constant in fluorescence quenching. The plot of $k_{\text {quench }}$ versus 5-PhITP concentration is hyperbolic (Figure $4 B$ ) and a fit of the data to the Michaelis-Menten equation provides a $K_{\mathrm{d} 5 \text {-PhiTP }}$ of $8 \pm 2 \mu \mathrm{M}$ and a $k_{\max q u e n c h}$ value of $38 \pm$ $5 \mathrm{~s}^{-1}$. The $K_{\mathrm{d}}$ of $8 \pm 2 \mu \mathrm{M}$ measured with the fluorescence assay is slightly lower than that of $14 \pm 3 \mu \mathrm{m}$ previously reported from a radiolabel assay. ${ }^{[5]}$ Despite this difference, the hyperbolic dependency of the rate constant on 5-PhITP concentration is indicative of a two-step rather than a single-step binding mechanism. ${ }^{[10]}$ It should also be noted that the $k_{\max \text { quench }}$ value of $38 \pm 5 \mathrm{~s}^{-1}$ is slower than that of $53 \pm 4 \mathrm{~s}^{-1}$ measured in the radiolabel assay. ${ }^{[5]}$ It is likely, however, that the lower value for fluorescence quenching reflects the inability to use saturating concentrations of 5-PhITP $(>32 \mu \mathrm{M})$ that are needed to measure a "maximal" rate constant.

Critical evaluation of these kinetic parameters provides insight into the dynamics of translesion DNA synthesis. For example, these values can be used to identify which kinetic step is rate-limiting for the incorporation of 5-PhITP opposite the lesion. This is best exemplified by using the kinetic mechanism
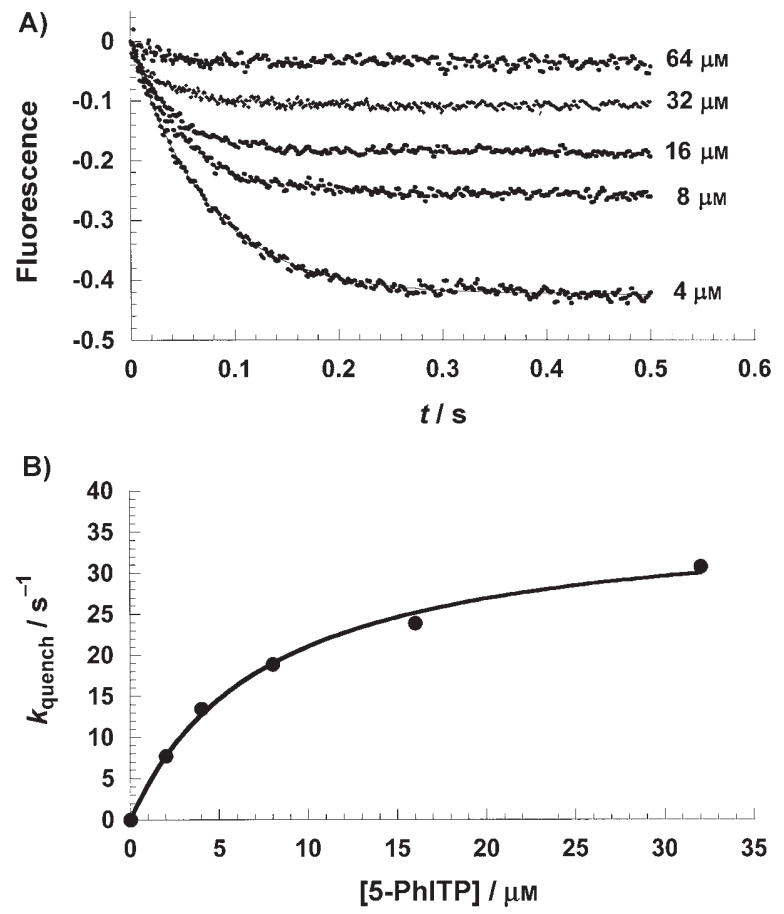

Figure 4. A) Dependency of 5 PhITP concentration on the observed rate con stant in fluorescence quenching as measured under single turnover condi tions. B) The observed rate constants in fluorescence quenching $(\bullet)$ were plotted against 5 PhITP concentration and fitted to the Michaelis Menten equation to determine $K_{\mathrm{d}}$ and $k_{\max }$ quench values.

outlined in Scheme 2. As illustrated, the radiolabel assay measures product formation $\left(\mathrm{DNA}_{n+1}\right)$ that occurs only after the phosphoryl transfer step (step 4). In contrast, the fluorescence assay is designed to detect intermediates including ternary complexes such as E:DNA:dXTP (step 2) and E:DNA:dXTP' (step 3) that form prior to phosphoryl transfer. If phosphoryl

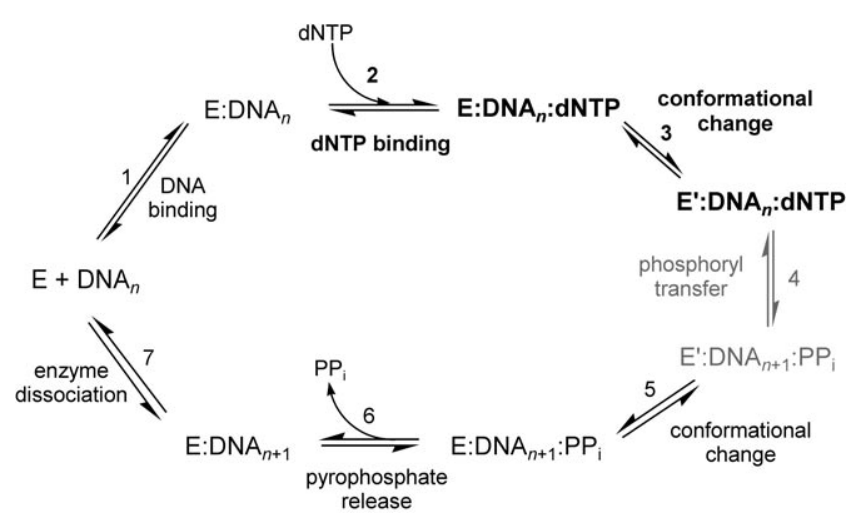

Scheme 2. Kinetic mechanism of gp43exo, the bacteriophage T4 DNA poly merase. Individual steps along the pathway for DNA polymerization are numbered and identified. Abbreviations: $\mathrm{E}=\mathrm{T} 4 \mathrm{DNA}$ polymerase, $\mathrm{DNA}_{n}=$ DNA substrate, $\mathrm{E}^{\prime}=$ conformational change in DNA polymerase, $\mathrm{PP}_{\mathrm{i}}=$ in organic pyrophosphate, and $\mathrm{DNA}_{n+1}=$ DNA product (DNA extended by one nucleobase). Steps highlighted as bold reflect those that can be identified through fluorescence quenching of the non natural nucleotide. Steps high lighted in gray reflect those that can be identified through product forma tion by using the radiolabel assay. 
transfer (step 4) is completely rate-limiting, then the rate constant measured by using the fluorescence assay (steps 2 and/ or 3 ) is predicted to be significantly faster than that measured by using the radiolabel assay (step 4). The data provided here, however, indicate that the rate constant for fluorescence quenching of 5-PhITP is slower than (or more likely equal to) that measuring product formation through the radiolabel assay ( $38 \mathrm{~s}^{-1}$ vs. $53 \mathrm{~s}^{-1}$, respectively). These data argue that phosphoryl transfer is not the rate-limiting step for incorporation opposite an abasic site since the rate constant for fluorescence quenching is not faster than that measuring product formation. This interpretation is consistent with data obtained from comparing product formation by using denaturing versus nondenaturing quenching agents. ${ }^{[5]}$ In this instance, identical amplitudes and rate constants in product formation were obtained regardless of quenching agent; this suggests that the rate-limiting step is the conformational-change step. Finally, the hyperbolic plot of 5-PhITP fluorescence quenching provided in this report is indicative of a two-step binding mechanism in which initial binding of 5-PhITP to the enzyme:DNA complex is followed by a subsequent conformational change to form the $\mathrm{E}^{\prime}: \mathrm{DNA}_{n+1}: 5$-PhITP complex..$^{[10]}$

The importance of the conformational-change step is that it is proposed to align the incoming dNTP into a precise geometrical configuration that then allows for phosphoryl transfer to occur. $^{[11]}$ As such, this kinetic step constitutes a kinetic point for error discrimination and contributes to the "induced fit" model of polymerase fidelity. ${ }^{[1]]}$ This induced-fit mechanism imposes discrimination against misincorporation events as they form premutational intermediates that disrupt or alter the geometry of the polymerase's active site to prevent extension of the primer. The fluorescence data described here provide additional evidence for the existence of this conformational change and indicate that this step limits the rate of nucleotide incorporation during translesion DNA synthesis. Equally important, the dynamics of the conformational change are influenced by $\pi$-electron density present on the non-natural nucleotide. $^{[\mathrm{dd}]}$

\section{Selectivity for translesion versus normal DNA synthesis}

The selectivity for the incorporation of 5-PhITP opposite an abasic site was evaluated by monitoring fluorescence changes of the non-natural nucleotide in the absence and presence of natural nucleoside triphosphates. In the absence of dNTPs, a $k_{\text {obs }}$ of $12.1 \pm 0.1 \mathrm{~s}^{-1}$ is measured for $4 \mu \mathrm{M} 5$-PhITP, while in the presence of $100 \mu \mathrm{M}$ dNTPs, a slower rate constant of $8.3 \pm$ $0.1 \mathrm{~s}^{-1}$ is measured. (Both time courses are provided in Figure S2). The ability of natural nucleotides to reduce the rate constant for fluorescence quenching of 5-PhITP is expected since the various natural nucleotides should compete with the non-natural nucleotide for binding to the polymerase:DNA complex. However, the inhibitory effect of $\sim 25 \%$ is exceedingly minimal considering that the concentration of natural dNTPs was maintained in 25-fold excess compared to that of the nonnatural nucleotide. This minimal inhibitory effect provides addi- tional evidence that 5-PhITP is more effectively incorporated opposite damaged DNA than natural nucleotides.

The selectivity for 5-PhITP incorporation opposite damaged versus unmodified DNA was also evaluated by measuring the incorporation kinetics opposite a templating thymine. The time course for fluorescence quenching of 5-PhITP opposite T (Figure $5 \mathrm{~A}$ ) differs substantially from that measuring incorporation opposite an abasic site (Figure $3 \mathrm{~A}$ ). In addition to being significantly slower, the time course for 5-PhITP incorporation opposite $\mathrm{T}$ is better defined as a double-exponential process rather than a single-exponential decay, as observed for incorporation opposite an abasic site. A fit of the data to a double-
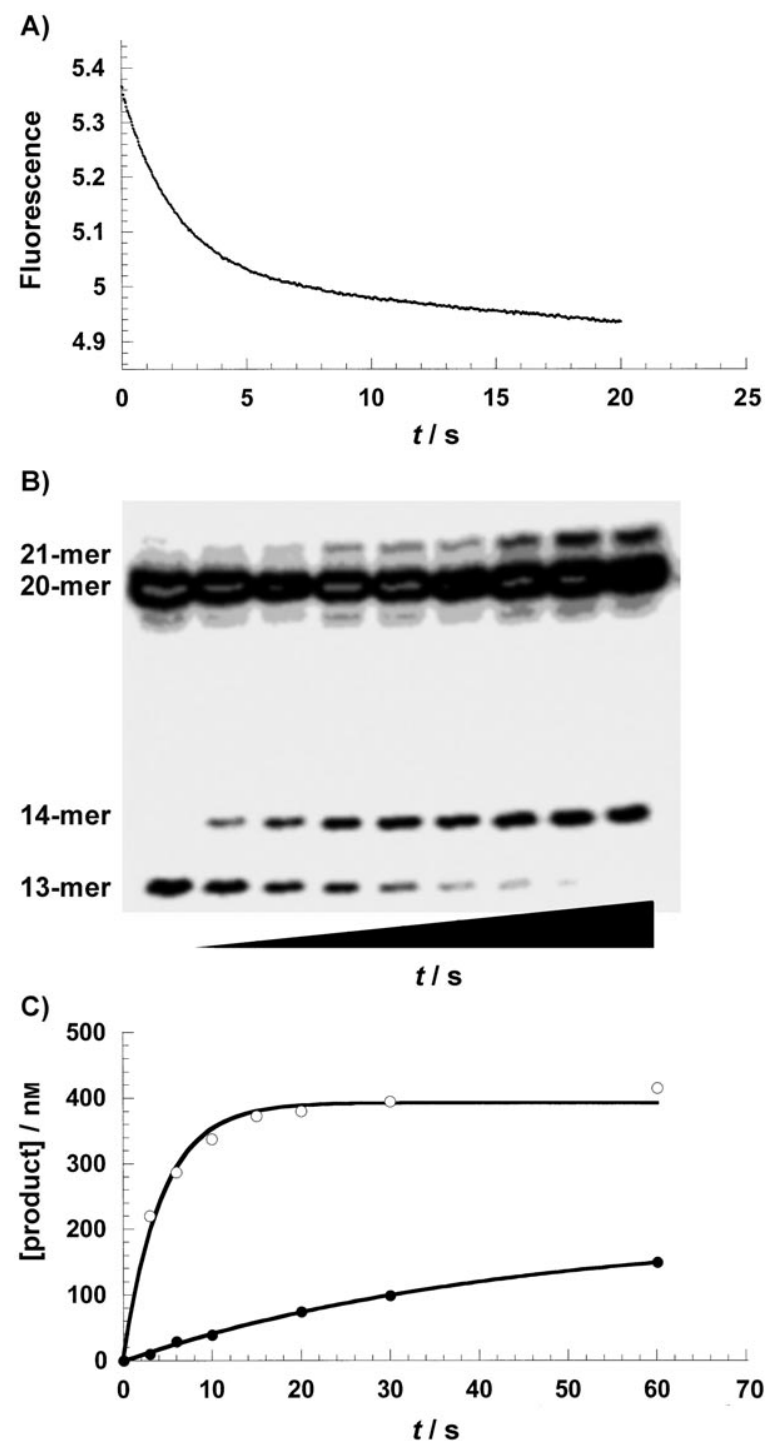

Figure 5. A) Time course monitoring the incorporation of 5 PhITP opposite a templating " $\mathrm{T}$ " by gp43 exo by using the fluorescence quenching assay. Assays were performed as described in the text. B) Denaturing gel electro phoretic monitoring of the incorporation of 5 PhITP opposite a templating " $\mathrm{T}$ " by gp43 exo by using the radiolabel extension assay. gp43 incorporates 5 PhITP opposite T, thus converting the 13 mer to a 14 mer. The extension of the 20 mer into a 21 mer represents the ability of gp43 exo to incorpo rate $5 \mathrm{PhITP}$ in a nontemplating fashion. C) Time course measuring the con version of 13 mer to 14 mer (incorporation of 5 PhITP opposite T; $\bigcirc$ ) as well as extension of 20 mer into 21 mer (blunt end incorporation of 5 PhITP; $\bullet$ ). 
exponential process provides two rate constants, a $k_{\text {quench } 1}$ of $0.35 \pm 0.05 \mathrm{~s}^{-1}$ and a second, slower $k_{\text {quench2 }}$ of $0.028 \pm$ $0.003 \mathrm{~s}^{-1}$. The molecular reason for this biphasic time course is evident when the kinetics of product formation are closely examined by using the ${ }^{32} \mathrm{P}$-radiolabel assay. As depicted in Figure $5 \mathrm{~B}$, gp43 incorporates 5-PhITP opposite T, resulting in the conversion of 13-mer to 14-mer. It is remarkable, however, that gp43 also extends the 20-mer to a 21-mer under the same reaction conditions. This enzyme activity represents "blunt-end" extension of the duplex DNA that is typically observed with low-fidelity DNA polymerases such as pol $\lambda$ and terminal deoxynucleotidyl transferase. ${ }^{[12]}$ The time course in product formation (Figure 5C) was used to define the rate constants in 14-mer (5-PhITP incorporation opposite " $\mathrm{T}$ ") and 21-mer production (incorporation of 5-PhITP at the "blunt-end"). The rate constant for 14-mer production is $0.24 \pm 0.4 \mathrm{~s}^{-1}$ while that for 21 -mer production is tenfold slower at $0.023 \pm 0.002 \mathrm{~s}^{-1}$. Comparing these rate constants to those measuring fluorescence quenching indicates that the value of $0.35 \mathrm{~s}^{-1}$ for $k_{\text {quench } 1}$ represents incorporation of 5-PhITP opposite " $\mathrm{T}$ " while the value of $0.028 \mathrm{~s}^{-1}$ for $k_{\text {quench2 }}$ corresponds to the incorporation of 5PhITP at the "blunt-end" of the DNA. In addition, the inclusion of $100 \mu \mathrm{M}$ dNTPs prevents the incorporation of 5-PhITP opposite $T$ but does not affect blunt-end extension of 5-PhITP. In fact, the absolute amount of 21-mer increases twofold since the polymerase now has an opportunity to incorporate 5PhITP at either blunt-end (Figure S3). The ability of gp43 to incorporate 5-PhITP at the blunt-end of DNA likely reflects the enhanced base-stacking capabilities of the non-natural nucleotide, and studies are currently underway to further delineate this unique behavior. Regardless of this phenomenon, it is clear that the $k_{\mathrm{obs}}$ of $\sim 0.3 \mathrm{~s}^{-1}$ measured for the incorporation of $4 \mu \mathrm{M} 5$-PhITP opposite $\mathrm{T}$ is 40 -fold slower than the rate constant of $12 \mathrm{~s}^{-1}$ measured for incorporation opposite an abasic site (vide supra). Collectively, these data indicate that 5-PhITP is more efficiently incorporated opposite an abasic site as opposed to templating nucleobase and supports the concept of using 5-PhITP as a selective probe to monitor translesion DNA synthesis.

\section{The dynamics of 5-PhITP incorporation opposite an abasic site are polymerase dependent}

Although the bacteriophage T4 DNA polymerase and Klenow fragment from E.coli are members of different polymerase families, they are similar in that they preferentially incorporate dATP opposite an abasic site. ${ }^{[13]}$ This similarity suggests that the dynamics of translesion DNA synthesis between the two polymerases should be comparable if not identical. To test this hypothesis, we characterized the ability of the E. coli Klenow fragment to incorporate 2-APTP and 5-PhITP opposite thymine or an abasic site. In contrast to the bacteriophage T4 DNA polymerase, the Klenow fragment is unable to incorporate 2APTP opposite an abasic site (using a concentration of $2 \mu \mathrm{M}$ ) although the polymerase does incorporate 2-APTP opposite T (data not shown). Likewise, the Klenow fragment is unable to incorporate 5-PhITP opposite $\mathrm{T}$ (data not shown). In this re- spect, it is surprising that the "high fidelity" T4 enzyme can insert the bulky, non-natural nucleotide opposite templating nucleobase while the Klenow fragment, which is proposed to replicate DNA with lower fidelity, does not. ${ }^{[14]}$

Despite these differences, the $E$. coli Klenow fragment is able to incorporate 5-PhITP opposite an abasic site as illustrated using the radiolabeled assay (Figure $6 \mathrm{~A}$ ) or the fluorescence
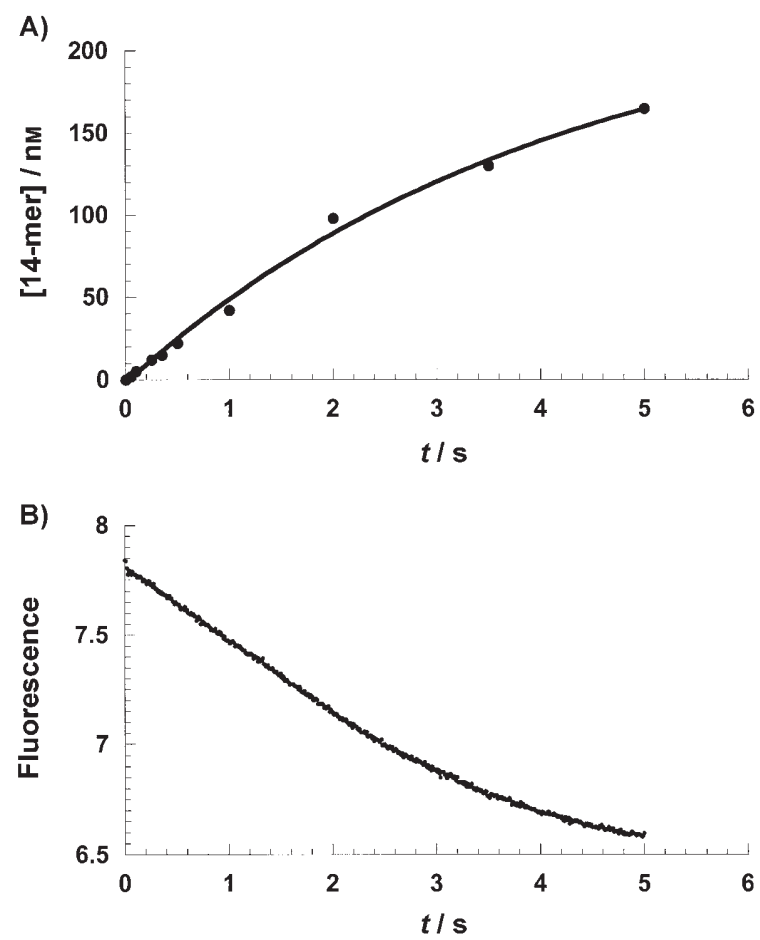

Figure 6. Time course monitoring the incorporation of 5 PhITP opposite an abasic site by the Klenow fragment of $E$. coli by using A) the radiolabel ex tension assay or B) the fluorescence quenching assay. Assays were per formed as described in the text.

quenching assay (Figure 6B). Both time courses are best defined as single-exponential processes. The $k_{\text {obs }}$ value from the radiolabeled assay is $0.17 \pm 0.01 \mathrm{~s}^{-1}$ while that from the fluorescence-quenching assay is $0.12 \pm 0.01 \mathrm{~s}^{-1}$. As is the case with the T4 polymerase, the Klenow fragment cannot extend beyond 5-PhITP once incorporated opposite an abasic site (data not shown). The similarity in rate constants suggests that the same kinetic step is being monitored and is most likely the conformational-change step preceding phosphoryl transfer. More importantly, the rate constant for 5-PhITP incorporation with Klenow fragment is $\sim 60$-fold slower than that measured with the T4 polymerase. Since single-turnover conditions were used to measure the rate constants in either case, we can calculate the $\Delta \Delta G^{0}$ for the incorporation of 5-PhITP. These values were calculated by using $\Delta \Delta G^{0}=R T \ln K$, where $R=$ $1.9872 \mathrm{cal} \mathrm{mol}^{-1} \mathrm{~K}, T=298 \mathrm{~K}$, and $K$ is the ratio of respective rate constants measured with gp43 exo $^{-}$versus the Klenow fragment. In this instance, the $\Delta \Delta G^{0}$ value of $2.42 \mathrm{kcal} \mathrm{mol}^{-1}$ was calculated by using the $k_{\text {obs }}$ value of $7.7 \mathrm{~s}^{-1}$ measured for gp43 exo ${ }^{-}$and the $k_{\text {obs }}$ value of $0.17 \mathrm{~s}^{-1}$ measured for the 
Klenow fragment. Unfortunately, the data presented here cannot determine whether this energetic difference reflects the contributions of ground-state binding, the conformational change, or a combination of the two. This will require further analysis of the kinetic parameters for the incorporation of 5PhITP by the Klenow fragment. Regardless, the data provided here demonstrate that the mechanism of translesion DNA synthesis appears to be similar between the two polymerases in which the conformational-change step limits the rate of incorporation opposite the abasic site. However, significant differences exist in the dynamics of the overall process, and these differences can be easily identified by using the fluorogenic properties of 5-PhITP.

\section{Conclusion}

This manuscript provides the first quantitative description of the use of a non-natural nucleotide, 5-PhITP, as a fluorogenic probe to monitor the dynamics of translesion DNA synthesis. We demonstrate that 5-PhITP is vastly superior to a commonly used fluorescent dNTP analogue, 2-aminopurine, for monitoring incorporation opposite an abasic site. This enhancement is due to the extremely favorable kinetic parameters for 5-PhITP incorporation opposite the DNA lesion compared to that of modified purines. Furthermore, the rate constants measured for 5-PhITP incorporation opposite an abasic site are polymerase dependent, a feature that can be exploited to provide further insight into the dynamics of translesion DNA synthesis. It will prove interesting to compare the kinetic behavior of various error-prone DNA polymerases that replicate abasic sites with higher efficiency with the activity of high-fidelity DNA polymerases, such as gp43, that are involved in chromosomal replication. Finally, this analogue might also be used as a probe to monitor the dynamics of incorporation opposite other forms of damaged DNA such as thymine dimers and bulky adducts that are proposed to processed like an abasic site. $^{[15]}$

\section{Experimental Section}

Materials: $\left[\gamma^{-32}\right.$ P]ATP was purchased from MP Biomedical (Irvine, CA). Unlabelled dNTPs (ultrapure) were obtained from Pharmacia. Magnesium acetate and Trizma base were from Sigma. Urea, acrylamide, and bis-acrylamide were from Aldrich. Oligonucleotides, including those containing a tetrahydrofuran moiety mimicking an abasic site, were synthesized by Operon Technologies (Alameda, CA). Single-stranded and duplex DNA were purified and quantified as previously described. ${ }^{[16]}$ All other materials were obtained from commercial sources and were of the highest available quality. The exonuclease-deficient mutant of gp43 (D219A mutation) was purified and quantified as previously described. ${ }^{[17]}$ The Klenow fragment of $E$. coli was purified to homogeneity as previously described. ${ }^{[18]}$ 2-Aminourine-2'-deoxyriboside $5^{\prime}$-triphosphate (2-APTP) was purchased from Trilink BioTechnologies (Mesa, CA). 5-Phenylindole $2^{\prime}$-deoxyribofuranoside $5^{\prime}$-triphosphate (5-PhITP) was synthesized as previously described. ${ }^{[5]}$

Enzyme assays: The assay buffer used in all kinetic studies consisted of Tris-OAc (25 mm; pH 7.5), KOAC (150 mm), and DTT (10 mm).
All assays were performed at $25^{\circ} \mathrm{C}$. Polymerization reactions were monitored by analysis of the products on $20 \%$ sequencing gels as previously described. ${ }^{[16]}$ Gel images were obtained with a Packard Phosphorlmager by using the OptiQuant software supplied by the manufacturer. Product formation was quantified by measuring the ratio of ${ }^{32} \mathrm{P}$-labelled extended and unextended primer. The ratios of product formation are corrected for substrate in the absence of polymerase (zero point). Corrected ratios are then multiplied by the concentration of primer/template used in each assay to yield total product.

Pre-steady-state nucleotide incorporation assays: A rapid quench instrument (KinTek Corporation, Clarence, PA) was used to monitor the time course of 5-PhITP incorporation with 13/20SPmer or 13/20T-mer as the DNA substrate. Experiments were performed under single-turnover reaction conditions such that the concentration of polymerase and nucleotide substrate were maintained in molar excess versus that of DNA substrate. A typical reaction was performed by rapidly mixing an aliquot of a preincubated solution of DNA polymerase (1000 nM; $250 \mathrm{pmol}$ of polymerase in a total volume of $250 \mu \mathrm{L}$ ) and DNA (500 nM; 125 pmol DNA in a total volume of $250 \mu \mathrm{L})$ in assay buffer containing EDTA $(100 \mu \mathrm{M})$ with an equal volume of solution containing nucleotide analogue $(2 \mu \mathrm{M})$ and $\mathrm{Mg}$ acetate $(10 \mathrm{~mm})$. After the solutions had been mixed in the rapid-quench-flow instrument for time intervals ranging from 0.01 to $30 \mathrm{~s}$, the reactions were quenched by the addition of EDTA ( $500 \mathrm{~mm}$ ) through the third syringe of the instrument. The reaction products were then analyzed, as described above. Data obtained for single-turnover DNA polymerization assays were fitted to Equation (1).

y $\quad A\left(1 e^{k t}\right)+C$

Here $A$ is the burst amplitude, $k$ is the observed rate constant for initial product formation, $t$ is time, and $C$ is the end point of the reaction.

Stopped-flow fluorescence analyses: Emission spectra for monitoring the insertion of 2-AP opposite thymine or an abasic site were obtained by using a stopped-flow instrument (KinTek Corporation, Clarence, PA). Samples were excited at $310 \mathrm{~nm}$, and fluorescence emission data were collected by using a cut-off filter that measures emission wavelengths greater than $340 \mathrm{~nm}$. (The maximal fluorescence emission for 2-APTP and 5-PhITP is $369 \mathrm{~nm}$ (data not shown).) Assays were as performed under single-turnover conditions, as described above for pre-steady-state polymerization reactions. A typical reaction was performed by rapidly mixing an aliquot of a preincubated solution of DNA polymerase (1000 nM; $500 \mathrm{pmol}$ of DNA polymerase in a total volume of $500 \mu \mathrm{L}$ ) and DNA (500 nм; 250 pmol DNA in a total volume of $500 \mu \mathrm{L}$ ) in assay buffer containing EDTA $(100 \mu \mathrm{M})$ with an equal volume of solution containing nucleotide analogue $(2 \mu \mathrm{M} ; 1 \mathrm{nmol}$ of nucleotide analogue in a total volume of $500 \mu \mathrm{L})$ and $\mathrm{Mg}$ acetate $(10 \mathrm{~mm})$. Data obtained for single-turnover DNA polymerization assays were fitted to Equation (2).

y $A e^{k t}+C$

Here $A$ is the burst amplitude, $k$ is the observed rate constant for initial product formation, $t$ is time, and $C$ is the end point of the reaction. 


\section{Acknowledgements}

This research was supported through funding from the National Institutes of Health to A.J.B. (CA118408).

Keywords: DNA polymerases - DNA synthesis - fluorescent probes $\cdot$ nucleotides

[1] a) A. Gentil, J. B. Cabral Neto, R. Mariage Samson, A. Margot, J. L. Imbach, B. Rayner, A. Sarasin, J. Mol. Biol. 1992, 227, 981 984; b) D. M. Wilson 3rd, D. Barsky, Mutat. Res. 2001, 485, 283307.

[2] A. J. Berdis, Biochemistry 2001, 40, 71807191.

[3] a) S. K. Randall, R. Eritja, B. E. Kaplan, J. Petruska, M. F. Goodman, J. Biol. Chem. 1987, 262, 6864 6870; b) S. Avkin, S. Adar, G. Blander, Z. Livneh, Proc. Natl. Acad. Sci. USA 2002, 99, 3764 3769; c) S. Shibutani, M. Take shita, A. P. Grollman, J. Biol. Chem. 1997, 272, 13916 13922; d) T. Paz Elizur, M. Takeshita, Z. Livneh, Biochemistry 1997, 36, 1766 1773; e) H. Ling, F. Boudsocq, R. Woodgate, W. Yang, Cell 2001, 107, 91102.

[4] a) M. Hogg, S. S. Wallace, S. Doublie, EMBO J. 2004, 23, 1483 1493; b) H. Hays, A. J. Berdis, Biochemistry 2002, 41, 4771 4778; c) E. Z. Rein eks, J. A. Berdis, Biochemistry 2004, 43, 393 404; d) X. Zhang, I. Lee, A. J. Berdis, Org. Biomol. Chem. 2004, 2, 1703 1711; e) X. Zhang, I. Lee, X. Zhou, A. J. Berdis, J. Am. Chem. Soc. 2006, 128, 143149.

[5] X. Zhang, I. Lee, A. J. Berdis, Biochemistry 2005, 44, 1310113110

[6] E. L. Rachofsky, J. B. Ross, R. Osman, Comb. Chem. High Throughput Screen 2001, 4, 675706.

[7] a) M. W. Frey, L. C. Sowers, D. P. Millar, S. J. Benkovic, Biochemistry 1995, 34, 9185 9192; b) C. A. Dunlap, M. D. Tsai, Biochemistry 2002, 41, 1122611235 ; c) V. Purohit, N. D. Grindley, C. M. Joyce, Biochemistry 2003, 42, 1020010211 ; d) L. B. Bloom, M. R. Otto, R. Eritja, L. J. Reha Krantz, M. F. Goodman, J. M. Beechem, Biochemistry 1994, 33, 7576
7586; e) R. P. Baker, L. J. Reha Krantz, Proc. Natl. Acad. Sci. USA 1998, 95, 3507 3512; f) M. R. Otto, L. B. Bloom, M. F. Goodman, J. M. Beechem, Biochemistry 1998, 37, 1015610163.

[8] The change in fluorescence intensity of 2 APTP represents incorpora tion since fluorescence quenching is not observed when 2 APTP is mixed with polymerase in the absence of DNA or DNA in the absence of polymerase (data not shown).

[9] a) J. T. Stivers, Nucleic Acids Res. 1998, 26, 3837 3844; b) E. L. Rachofsky, E. Seibert, J. T. Stivers, R. Osman, J. B. Ross, Biochemistry 2001, 40, 957 967.

[10] a) K. A. Johnson, Methods Enzymol. 1995, 249, 38 61; b) S. P. Gilbert, A. T. Mackey, Methods 2000, 22, 337354

[11] M. J. Donlin, S. S. Patel, A. K. Johnson, Biochemistry 1991, 30, 538546

[12] a) I. Shevelev, G. Blanca, G. Villani, K. Ramadan, S. Spadari, U. Hübscher, G. Maga, Nucleic Acids Res. 2003, 31, 6916 6925; b) J. M. Clark, Nucleic Acids Res. 1988, 16, 96779686.

[13] a) E. C. Freidberg, W. J. Feaver, L. V. Gerlach, Proc. Natl. Acad. Sci. USA 2000, 97, 56815683 ; b) R. A. Beckman, A. S. Mildvan, L. A. Loeb, Bio chemistry 1985, 24, 58105817 ; c) H. Ide, H. Murayama, S. Sakamoto, K. Makino, K. Honda, H. Nakamuta, M. Sasaki, N. Sugimoto, Nucleic Acids Res. 1995, 23, 123129.

[14] B. T. Eger, S. J. Benkovic, Biochemistry 1992, 31, 92279236

[15] J. S. Taylor, Mutat. Res. 2002, 510, 5570.

[16] T. L. Capson, J. A. Peliska, B. F. Kaboord, M. W. Frey, C. Lively, M. Dahl berg, J. S. Benkovic, Biochemistry 1992, 31, 1098410994.

[17] a) M. W. Frey, N. G. Nossal, T. L. Capson, J. S. Benkovic, Proc. Natl. Acad. Sci. USA 1993, 90, 2579 2583; b) J. Rush, H. W. Konigsberg, Prep. Bio chem. 1989, 19, 329340.

I181 C. M. Jovce. V. Derbvshire. Methods Enzvmol. 1995. 262, 313.

Received: March 31, 2006

Revised: September 13, 2006

Published online on November 8, 2006 